\title{
Mortality of older patients with dementia after surgery for chronic subdural hematoma: a nationwide study
}

\section{Tommiska, Pihla}

2020-10-06

Tommiska , P , Korja , M , Siironen , J , Kaprio , J \& Raj , R 2020 , ' Mortality of older patients with dementia after surgery for chronic subdural hematoma: a nationwide study ' , pÿAge and Ageing , vol. 50 , no. 3 , pp. 815821 . https://doi.org/10.1093/ageing/afaa193

http://hdl.handle.net/10138/337779

https://doi.org/10.1093/ageing/afaa193

acceptedVersion

Downloaded from Helda, University of Helsinki institutional repository.

This is an electronic reprint of the original article.

This reprint may differ from the original in pagination and typographic detail.

Please cite the original version. 
This is a pre-copyedited, author-produced version of an article accepted for publication in Age and Ageing following peer review. The version of record "Pihla Tommiska, Miikka Korja, Jari Siironen, Jaakko Kaprio, Rahul Raj, M ortality of older patients with dementia after surgery for chronic subdural hematoma: a nationwide study, Age and Ageing, Volume 50, Issue 3, M ay 2021, Pages 815-821" is available online at: https://doi.org/10.1093/ageing/afaa193 


\section{Mortality of older patients with dementia after surgery for chronic subdural hematoma: a nationwide study}

\section{ABSTRACT}

BACKGROUND: Dementia is associated with an excess risk of death but mortality after chronic subdural hematoma (CSDH) evacuation in elderly with dementia is unknown. We assessed the association between dementia and one-year case-fatality in elderly persons undergoing $\mathrm{CSDH}$ evacuation.

METHODS: We conducted a nationwide Finnish cohort study including all elderly persons ( $\geq 60$ years) undergoing CSDH evacuation during 1997-2014 (referred to as cases). We identified controls, without a diagnosis of $\mathrm{CSDH}$, that were matched for age, sex and year of first hospitalization with a new dementia diagnosis. We identified cases and controls with a pre-existing diagnosis of dementia. Outcome was 12-month mortality. Mortality was compared in case-only and case-control analyses.

RESULTS: Of 7,621 included cases, 885 (12\%) had a pre-existing diagnosis of dementia. The proportion of cases increased from $9.7 \%$ in $1997-2002$ to $12.2 \%$ in $2012-2014$ $(\mathrm{p}=0.038$ for trend). In the case-analysis, dementia independently associated with oneyear case-fatality (dementia vs. no dementia odds ratio [OR] 1.50, 95\% confidence interval [CI] 1.26-1.78). Sensitivity analysis suggested the association to be strongest for those 60-69 years old (OR 3.21, 95\% Cl 1.59-6.47). In the case-control matched analysis, oneyear mortality was $26 \%$ in the dementia CSDH surgery group compared to $16 \%$ in dementia non-CSDH controls $(p<0.001)$.

CONCLUSIONS: Dementia is a significant risk factor for one-year mortality after CSDH surgery in the elderly. The proportion of elderly CSDH patients having a pre-existing diagnosis of dementia is increasing. Thus, there is a need for improved evidence regarding the indications and benefits of CSDH evacuation among elderly persons.

KEYWORDS: chronic subdural hematoma, dementia, mortality, nationwide study, neurosurgery 


\section{INTRODUCTION}

Chronic subdural hematoma (CSDH) has become one of the most common neurosurgical disorders, mainly due to the ageing population with an increased risk for falls and the concomitant increased use of antithrombotic medication $[1,2,3]$. In case of a CSDH causing symptoms and neurological signs, surgery is the treatment of choice [4]. The ageing population is the key factor behind the increasing number of people with dementia [5]. The global incidence of dementia has been estimated to be $4.2 / 100,000$ for those $\geq 65$ years [6]. Further, it has been estimated that the prevalence of dementia will triple by 2050 [5], despite some evidence that the incidence of dementia may not be increasing, especially in high-income countries $[7,8]$. Still, dementia is rapidly growing into a major contributor to demand for healthcare with associated costs and increased disability [9]. This is also reflected in neurosurgical practice, where patients with disorders such as acute traumatic brain injury [10], glioblastoma [11], degenerative cervical spine disease [12], and CSDH [13] are getting older and older, partly due to the ageing trends but also because of the ability of modern medicine to treat the frailer elderly successfully. Among persons $\geq 65$ years, the CSDH incidence has been described to be between 29-64 per $100,000[13,14,15]$.

The rationale for surgical evacuation of CSDH is alleviation of symptoms caused by the mass effect of the CSDH. In most surgical procedures, the benefit-risk ratio decreases among older patients [16]. Although, CSDH evacuation is considered a minor intervention, one-year mortality among the elderly with CSDH has been reported to be as high as $32 \%$ [17]. Although the procedure may not be that invasive, the high mortality probably reflects high age, comorbidities and frailty $[17,18,19]$. Thus, CSDH may be a late manifestation of these factors ultimately leading to death. 
Currently, there are few studies looking at elderly patients treated for CSDH, but no studies looking specifically at the relationship between age, dementia and outcome after CSDH surgery. To address this unmet demand, we aimed to assess the occurrence of $\mathrm{CSDH}$ evacuation in elderly patients and to assess one-year case-fatality after CSDH evacuation in patients with and without a pre-existing diagnosis of dementia. We hypothesized that the proportion of patients with a pre-existing diagnosis of dementia undergoing CSDH evacuation had increased and that one-year case-fatality would be markedly higher in this patient group. Furthermore, we hypothesized that one-year casefatality would be higher in patients with dementia undergoing CSDH evacuation compared to matched controls with dementia but without a diagnosis of $\mathrm{CSDH}$. 


\section{METHODS}

\section{Study design}

We used the nationwide Finnish Care Register for Health Care, which we have described previously in detail [20]. (Appendix 1)

\section{Case definition}

We defined cases as elderly adults ( $\geq 60$ years) with a new event of CSDH evacuation between 1 January 1997 and 31 December 2014 (Figure 1). (Appendix 1)

\section{Definition of exposure}

We defined exposure as having a pre-existing diagnosis of dementia. Thus, "exposed cases" are defined as persons undergoing CSDH evacuation with a pre-existing diagnosis of dementia, while "non-exposed cases" are defined as persons undergoing CSDH evacuation but without a diagnosis of dementia. (Appendix 1)

\section{Exposed controls}

We defined exposed controls as persons with a diagnosis of dementia without a history of hospitalization due to head injury. We matched every exposed case with four exposed controls based on age, sex and year of first hospitalization with a new dementia diagnosis. (Appendix 1)

\section{Definition of outcome}

The study population was followed up from time of operation until death or end of follow-up on 31 December 2017, based on vital status data from the Population Register Centre. We defined all-cause one-year mortality as the outcome of interest. 
Statistical analyses (Appendix 1)

Ethical Statement (Appendix 1) 


\section{RESULTS}

The study population consisted of 7,621 cases and 2,633 controls. There were 885 exposed cases and 6,736 non-exposed cases (Figure 1). Overall median age was 77 years (IQR 70, 83) and 34\% were female. The vast majority of all CSDH evacuations (89\%) were performed in a University hospital. One in five of the cases underwent a second CSDH evacuation within one-year of the primary operation. During the study period median age increased (76 years to 78 years) and fewer operations were carried out in non-University Central hospitals (from 19\% to 5\%) (Appendix 2).

Total follow-up time from the first CSDH evacuation to death or end of 2017 was 43,210 patient-years. Median follow-up was 4.8 years (IQR 2.2-8.2 years). During the whole follow-up, 4,916 out of 7,621 cases died (65\%). Of exposed cases, $88 \%$ died during the follow-up, compared to $61 \%$ of non-exposed cases $(p<0.001)$.

Overall one-year case-fatality was $16 \%$. Cases dying within one-year of CSDH evacuation were older (median age 82 vs. 76 years), more often treated in a non-University Central hospital (13\% vs. $10 \%)$ than in a University hospital, underwent fewer re-evacuations (15\% vs. $21 \%$ ), and had more often a diagnosis of dementia (19\% vs. $10 \%$ ) compared to cases not dying within one-year (Table 1).

Totally 885 cases (12\%) had a pre-existing diagnosis of dementia or received the diagnosis within one-year of the primary CSDH evacuation (exposed cases). These exposed cases were older (median age 82 years vs. 76 years), more often female ( $48 \%$ vs. $33 \%)$, more often operated in a central hospital (13\% vs. $10 \%$ ) and underwent fewer CSDH re-operations (17\% vs. $20 \%$ ) compared to non-exposed cases (Table 2). One-year 
case-fatality was significantly higher in exposed cases compared to non-exposed cases $(26 \%$ vs. $15 \%, p<0.001)$.

\section{Hospital-based occurrence}

The occurrence of CSDH evacuation among all age-groups ( $\geq 60$ years) was 35.4 per 100,000. The occurrence of CSDH evacuation increased from 29.7/100,000 in 1997-2002 to $42.7 / 100,000$ in $2012-2014$. The occurrence of CSDH evacuation increased especially among those $80-89$ years (from $60.4 / 100,000$ in $1997-2002$ to $95.8 / 100,000$ in $2012-2014$ ) and those 90 years or older (from 58.8/100,000 in 1997-2002 to $111 / 100,000$ in 20122014). The proportion of exposed cases increased from $9.7 \%$ in $1997-2002$ to $12.2 \%$ in 2012-2014 ( $p$ for trend=0.038) (Figure 2).

\section{Case-only analysis}

Including all cases, exposure to dementia was associated with an increased risk of oneyear case-fatality with an OR of $1.50(95 \% \mathrm{Cl} 1.26-1.78, \mathrm{p}<0.001)$ (Table 3). Female sex (OR $0.81,95 \% \mathrm{Cl} 0.71-0.92$ ), CSDH re-operation within one-year (OR 0.67, 95\% Cl 0.560.79) and a more recent study year significantly associated with a reduced risk of one-year case-fatality, while higher age (OR 1.08, 95\% Cl 1.06-1.08) associated with an increased risk of one-year case-fatality (Appendix 3).

Exposure to dementia was associated with the highest risk of death among cases aged 60-69 years (OR 3.21, 95\% Cl 1.59-6.47, $\mathrm{p}=0.001$ ) (Table 3). This association weakened with age, such that there were no association between exposure to dementia and risk of one-year case-fatality after CSDH evacuation for persons $\geq 90$ years (OR 1.20, $p=0.47$ ). 
The exposure of dementia was associated with one-year case-fatality with an HR of 1.38 (95\% 1.20-1.60, $\mathrm{p}<0.001)$ in the Cox proportional Hazards model (adjusting for age, sex, hospital level of care, re-operation and primary operation year).

\section{Exposed case-control analysis}

For the 885 exposed cases, we identified 832 (94\%) sets with at least one age, sex, and year of first hospitalization with a new dementia diagnosis matched exposed control. In detail, 585 out of 832 exposed cases (70\%) had four exposed controls, 143 out of 832 exposed cases (17\%) had three exposed controls, 60 out of 832 exposed cases $(7 \%)$ had two exposed controls and 44 out of 832 exposed cases $(5 \%)$ had one exposed control. Thus, there were 2,933 exposed controls in total.

One-year mortality was $26 \%(n=216 / 832)$ in the exposed case group compared to $16 \%$ $(n=459 / 2,933)$ in the exposed control group $(p<0.001)$. 


\section{DISCUSSION}

\section{Key findings}

In this nationwide study, we show for the first time that dementia is an independent risk factor for one-year mortality in elderly patients undergoing CSDH evacuation. The association between dementia and mortality was strongest for those aged 60-69 years. Further, in the case-control analysis, we showed that patients with dementia undergoing $\mathrm{CSDH}$ evacuation had a significantly higher risk of death compared to those with dementia but without a diagnosis of CSDH. Also, during the study period, the occurrence of CSDH evacuation for those $\geq 60$ years increased by $44 \%$ and the increase was especially evident in those 80-89 years and those $\geq 90$ years, where the occurrence of CSDH increased by $59 \%$ and $89 \%$, respectively. Furthermore, there was a significant trend towards a higher proportion of patients undergoing CSDH evacuation having a pre-existing diagnosis of dementia. Interestingly, female sex was associated with a lower one-year case-fatality. It is possible that this reflects sex-related differences in comorbidities and life-expectancy, rather than true sex-related differences.

\section{Comparison of the findings to previous studies}

Very few studies have assessed the relationship between dementia and outcome after CSDH evacuation. For example, Abe and colleagues did not find any association between dementia and poor post-operative functional outcome [23]. Still, there are studies looking at outcome after surgical treatment of elderly CSDH patients. Some studies have shown higher mortality and morbidity rates in elderly patients compared to young patients $[17,19,24,25,26]$. Several studies, however, found no independent association between age and outcome in elderly CSDH patients $[27,28,29]$. 
In our study, we assessed a longer-term mortality rate, one-year after surgery, and the difference in mortality rates between dementia and non-dementia CSDH patients was significant. The one-year mortality of CSDH patients with dementia (26\%) is comparable to overall one-year mortality of elderly hip fracture patients (27\%) [30]. Both hip fracture and $\mathrm{CSDH}$ may be considered sentinel health events and markers of a decline in health of elderly patients [31,32]. Further, dementia in itself is considered a malignant disorder with excess risk of death $[33,34,35]$. Thus, it is not surprising that dementia is associated with an increased mortality in CSDH patients. Furthermore, the case-control analysis showed that dementia patients undergoing CSDH surgery had a significantly higher one-year mortality than dementia patients without CSDH. It is possible that symptomatic CSDHs may aggravate and unmask other underlying significant medical conditions that may increase risk of death as well, partly explaining the higher mortality rate [17]. Another factor possibly explaining the higher mortality rate among dementia patients is delay in diagnosis. Delay in diagnosis and, thus, poorer functional status at admission is known to associate with poor outcome and mortality after CSDH surgery [36].

The increase in the proportion of patients with comorbid dementia undergoing CSDH surgery is in line with a recent study by Rauhala and colleagues. They reported the proportion of patients with dementia and CSDH increasing from 3\% in 1990-1995 to 13\% in 2011-2015 [13], although these results should be cautiously compared with ours as their study included adult patients of all ages and even conservatively treated patients.

\section{Strengths and limitations}

This is the first nationwide hospital-based study looking into the association between dementia and mortality after CSDH evacuation. The nationwide coverage using high- 
quality and validated registers strengthens the findings $[37,38]$. A strength of this study is the employment of a matched case-control group, which enables comparison in mortality rates between dementia patients with and without CSDH. For $94 \%$ of patients, we were able to obtain at least one control case, and the number of cases and controls included in the study reached 10,554 in total. Another strength is that the study was conducted in a country where the social welfare and health care system is tax-funded and personal insurance status and socioeconomic factors do not impact availability, method or quality of treatment. Accordingly, our analysis provides a comprehensive view of the whole hospitalized patient population in Finland.

There are some limitations that should be mentioned. All large-scaled register-based studies include to a degree some diagnostic inaccuracies, coding errors and confounding factors that cannot be controlled for. Further, the most obvious limitation of any largescaled register-based study is that we cannot draw any causative relationships but only assess associations. For example, we cannot exclude differences in other pre-existing comorbidities or functional capacity between CSDH cases with and without dementia that may explain differences in mortality. Likewise, a similar possibility of confounding applies to the case-control matching. However, the nationwide coverage and the large study group size decrease the risk of such confounding.

The Care Register for Health Care includes only hospitalized patients with a discharge diagnosis including dementia, which makes it plausible that we have missed patients diagnosed and treated in the outpatient setting [20]. For example, in clinical practice, an ICD diagnosis is not always registered for dementia patients and the disease might only be mentioned in their medical charts. Thus, these cases remain unrecognized when 
searching for dementia diagnoses in the Care Register for Health Care and, thus, dementia is probably more frequent than recorded in the present study. For example, in our retrospective study approximately one in five patients undergoing CSDH evacuation had a diagnosis or a mention of dementia or memory impairment in their medical charts [39]. However, although the non-exposed cases (non-dementia) group may include patients with dementia, the mortality in exposed cases group was still significantly higher.

Moreover, we dichotomized patients into having a diagnosis of dementia or not without being able to account for severity. However, in the case-control analysis, one of the matching criteria was time since diagnosis. Still, the control group, as well, represents a cohort of patients being hospitalized for some reason (other than head injury) and having a discharge diagnosis including dementia. Yet, this is probably why the control group serves as a suitable control group for the CSDH evacuated cases, as both groups had all been hospitalized before. Further, changes in the diagnostic criteria also possibly affect our results and thus the increased proportion of dementia patients undergoing CSDH evacuation may partly be explained by changes in dementia diagnostics that have occurred [40].

\section{Future directions}

Dementia among CSDH patients is still a relatively uncommon entity. For example, in 2014 there were only 72 patients with pre-existing ICD-10 dementia diagnosis undergoing CSDH evacuation in Finland. However, 14,500 persons over the age of 64 years are annually diagnosed with dementia in Finland [41], and the world-wide prevalence of dementia is estimated to steadily increase [5]. At the same time, supposing that the incidence of CSDH continues to increase, we can expect the number of patients with 
dementia undergoing CSDH evacuation to rise in the future. Although mortality rates are high, the surgery seems to be indicated in order to treat neurological symptoms, improve quality of life and alleviate care intensity. It is worth mentioning that in Finland, CSDH evacuation is almost entirely performed by burr-hole craniostomies in local anesthesia, avoiding the possible complications associated with general anesthesia $[42,43]$. This is especially relevant for elderly patients often having multiple comorbidities, which can predispose to complications in general anesthesia. Still, there is a need for studies in order to optimize treatment of CSDH for elderly patients with dementia. 


\section{CONCLUSION}

The proportion of elderly CSDH patients having a pre-existing diagnosis of dementia is increasing. Dementia is an independent significant risk factor for one-year case-fatality after CSDH evacuation in the elderly, especially among men. The occurrence of CSDH surgery in elderly patients may be considered as marker of decline in general health with an associated excess risk of death. However, CSDH evacuation might be indicated to improve quality of life in elderly patients with dementia. Still, there is a need for improved evidence regarding the indications and benefits of CSDH evacuation among elderly persons with and without dementia. 


\section{REFERENCES}

1. Connolly BJ, Pearce LA, Hart RG. Vitamin K Antagonists and Risk of Subdural Hematoma. Stroke 2014; 45: 1672-1678.

2. Gaist D, García Rodríguez LA, Hellfritzsch M et al. Association of Antithrombotic Drug Use With Subdural Hematoma Risk. JAMA 2017; 317: 836.

4. Kolias AG, Chari A, Santarius T, Hutchinson PJ. Chronic subdural haematoma: modern management and emerging therapies. Nat Rev Neurol 2014; 10: 570-578.

5. Prince M, Bryce R, Albanese E, Wimo A, Ribeiro W, Ferri CP. The global prevalence of dementia: A systematic review and metaanalysis. Alzheimer's Dement 2013; 9: 63-75.e2.

6. Pringsheim T, Fiest K, Jette $\mathrm{N}$. The international incidence and prevalence of neurologic conditions: how common are they? Neurology 2014; 83: 1661-4.

7. Derby CA, Katz MJ, Lipton RB, Hall CB. Trends in Dementia Incidence in a Birth Cohort Analysis of the Einstein Aging Study. JAMA Neurol 2017; 74: 1345-1351.

9. Prince MJ, Wu F, Guo Y et al. The burden of disease in older people and implications for health policy and practice. Lancet 2015; 385: 549-562.

10. Lindfors M, Vehviläinen J, Siironen J, Kivisaari R, Skrifvars MB, Raj R. Temporal changes in outcome following intensive care unit treatment after traumatic brain injury: a 17-year experience in a large academic neurosurgical centre. .

11. Korja M, Raj R, Seppä $\mathrm{K}$ et al. Glioblastoma survival is improving despite increasing incidence rates: a nationwide study between 2000 and 2013 in Finland. Neuro Oncol 2019; 21 : 370-379.

12. Kotkansalo A, Leinonen $\mathrm{V}$, Korajoki M, Salmenkivi J, Korhonen K, Malmivaara A. Surgery for degenerative cervical spine disease in Finland, 1999-2015. : 1999_ 2015.

13. Rauhala M, Luoto TM, Huhtala $\mathrm{H}$ et al. The incidence of chronic subdural hematomas from 1990 to 2015 in a defined Finnish population. J Neurosurg 2019;

14. Adhiyaman V, Chattopadhyay I, Irshad F, Curran D, Abraham S. Increasing incidence of chronic subdural haematoma in the elderly. QJM 2017; 110: 375-378.

15. Kudo H, Kuwamura K, Izawa I, Sawa H, Tamaki N. Chronic Subdural Hematoma in Elderly People: Present Status on Awaji Island and Epidemiological Prospect. .

16. Reponen E, Korja M, Niemi T, Silvasti-Lundell M, Hernesniemi J, Tuominen H. Preoperative identification of neurosurgery patients with a high risk of in-hospital complications: a prospective cohort of 418 consecutive elective craniotomy patients. J Neurosurg 2015; 123: 594-604.

17. Miranda LB, Braxton E, Hobbs J, Quigley MR. Chronic subdural hematoma in the elderly: not a benign disease. J Neurosurg 2011; 114: 72-76.

19. Ramachandran R, Hegde T. Chronic subdural hematomas-causes of morbidity and mortality. Surg Neurol 2007; 67: 367-372.

20. Raj R, Kaprio J, Korja M, Mikkonen ED, Jousilahti P, Siironen J. Risk of hospitalization with neurodegenerative disease after moderate-to-severe traumatic brain injury in the working-age population: A retrospective cohort study using the Finnish national health registries. 2017; 
23. Abe $\mathrm{Y}$, Maruyama $\mathrm{K}$, Yokoya $\mathrm{S}$ et al. Outcomes of chronic subdural hematoma with preexisting comorbidities causing disturbed consciousness. J Neurosurg 2017; 126: 1042-1046.

24. Christopher E, Poon MTC, Glancz LJ et al. Outcomes following surgery in subgroups of comatose and very elderly patients with chronic subdural hematoma. Neurosurg Rev 2019; 42: 427-431.

27. Bartek J, Sjåvik K, Ståhl $F$ et al. Surgery for chronic subdural hematoma in nonagenarians: A Scandinavian population-based multicenter study. Acta Neurol Scand 2017; 136: 516-520.

28. De Bonis $\mathrm{P}$, Olei $\mathrm{S}$, Mongardi $\mathrm{L}$ et al. Chronic subdural hematoma in patients aged 80 years and older: A two-centre study. Clin Neurol Neurosurg 2018; 170: 88-92.

30. Panula J, Pihlajamäki H, Mattila VM et al. Mortality and cause of death in hip fracture patients aged 65 or older: a population-based study. BMC Musculoskelet Disord 2011; 12: 105.

32. Dumont TM, Rughani Al, Goeckes T, Tranmer BI. Chronic Subdural Hematoma: A Sentinel Health Event. World Neurosurg 2013; 80: 889-892.

33. Baldereschi M, Di Carlo A, Maggi S et al. Dementia is a major predictor of death among the Italian elderly. ILSA Working Group. Italian Longitudinal Study on Aging. Neurology 1999; 52: 709-13.

36. Santarius T, Kirkpatrick PJ, Ganesan D et al. Use of drains versus no drains after burr-hole evacuation of chronic subdural haematoma: a randomised controlled trial. Lancet 2009; 374: 1067-1073.

37. Keskimäki I, Aro S. Accuracy of data on diagnoses, procedures and accidents in the Finnish Hospital Discharge Register. Int Jx Heal Sci 1991; 2: 15-21.

38. Sund R. Quality of the Finnish Hospital Discharge Register: A systematic review. Scand J Public Health 2012; 40: 505-515.

39. Tommiska P, Lönnrot K, Raj R, Luostarinen T, Kivisaari R. Transition of a Clinical Practice to Use of Subdural Drains after Burr Hole Evacuation of Chronic Subdural Hematoma: The Helsinki Experience. World Neurosurg 2019;

41. Erkinjuntti T, Remes A, Rinne J, Soininen H, eds. Muistisairaudet. 2nd ed. Kustannus oy Duodecim, 2015.

43. Surve RM, Bansal S, Reddy M, Philip M. Use of Dexmedetomidine Along With Local Infiltration Versus General Anesthesia for Burr Hole and Evacuation of Chronic Subdural Hematoma (CSDH). J Neurosurg Anesthesiol 2017; 29: 274-280. 
Table 1: Baseline characteristics for cases with a fatal and non-fatal one-year outcome

\begin{tabular}{|l|l|l|l|l|}
\hline Variable & $\begin{array}{l}\text { All cases } \\
(\mathrm{n}=7,621)\end{array}$ & $\begin{array}{l}\text { Survivors } \\
(\mathrm{N}=6,381)\end{array}$ & $\begin{array}{l}\text { Non-survivors } \\
(\mathrm{N}=1,240)\end{array}$ & $\mathbf{p}$-value \\
\hline Age, median (IQR) & $77(70-83)$ & $76(70-72)$ & $82(75-86)$ & $<0.001$ \\
\hline $60-69$ & $1,738(23 \%)$ & $1,595(25 \%)$ & $143(12 \%)$ & $<0.001$ \\
\hline $70-79$ & $2,896(38 \%)$ & $2,537(40 \%)$ & $359(29 \%)$ & \\
\hline $80-89$ & $2,558(34 \%)$ & $1,970(31 \%)$ & $588(47 \%)$ & \\
\hline $90+$ & $429(5 \%)$ & $279(4 \%)$ & $150(12 \%)$ & \\
\hline Sex & & & & \\
\hline Female & $2,611(34 \%)$ & $2,172(34 \%)$ & $439(35 \%)$ & 0.35 \\
\hline M ale & $5,010(66 \%)$ & $4,209(66 \%)$ & $801(65 \%)$ & \\
\hline Hospital level & & & & \\
\hline University hospital & $6,807(89 \%)$ & $5,725(90 \%)$ & $1,082(87 \%)$ & 0.010 \\
\hline Central hospital & $814(11 \%)$ & $654(10 \%)$ & $158(13 \%)$ & \\
\hline Primary operation year (quartiles) & \multicolumn{3}{|l}{} & \\
\hline $1997-2002$ & $1,839(24 \%)$ & $1,516(24 \%)$ & $323(25 \%)$ & 0.23 \\
\hline $2003-2007$ & $1,921(25 \%)$ & $1,616(25 \%)$ & $305(25 \%)$ & \\
\hline $2008-2011$ & $2,020(27 \%)$ & $1,713(27 \%)$ & $307(25 \%)$ & \\
\hline $2012-2014$ & $1,841(24 \%)$ & $1,536(24 \%)$ & $305(25 \%)$ & \\
\hline Re-operationa & $1,526(20 \%)$ & $1,336(21 \%)$ & $190(15 \%)$ & $<0.001$ \\
\hline Dementiab & $885(12 \%)$ & $654(10 \%)$ & $231(19 \%)$ & $<0.001$ \\
\hline $\begin{array}{l}\text { aRe-evacuation of a chronic subdural hematoma within 1 year of the primary evacuation } \\
\text { bementia diagnosis before or within one-year of the chronic subdural hematoma evacuation }\end{array}$ \\
\hline
\end{tabular}


Table 2: Baseline characteristics for cases exposed and not exposed to dementia

\begin{tabular}{|l|l|l|l|}
\hline Variable & $\begin{array}{l}\text { Dementia } \\
(\mathrm{n}=885)\end{array}$ & $\begin{array}{l}\text { No dementia } \\
(\mathrm{n}=6,736)\end{array}$ & p-value \\
\hline Age, median (IQR) & $82(78-86)$ & $76(69-82)$ & $\varangle 0.001$ \\
\hline $60-69$ & $53(6 \%)$ & $1,685(25 \%)$ & $\varangle 0.001$ \\
\hline $70-79$ & $239(27 \%)$ & $1,657(39 \%)$ & \\
\hline $80-89$ & $494(56 \%)$ & $2,064(31 \%)$ & \\
\hline $90+$ & $99(11 \%)$ & $330(5 \%)$ & \\
\hline Sex & & & \\
\hline Female & $425(48 \%)$ & $2,186(33 \%)$ & $\varangle 0.001$ \\
\hline Male & $460(52 \%)$ & $4,550(68 \%)$ & \\
\hline Hospital level & & & \\
\hline University hospital & $766(87 \%)$ & $6,041(90 \%)$ & 0.005 \\
\hline Central hospital & $119(13 \%)$ & $695(10 \%)$ & \\
\hline Primary operation year (quartiles) & & & \\
\hline $1997-2002$ & $179(20 \%)$ & $1,660(25 \%)$ & 0.036 \\
\hline $2003-2007$ & $239(27 \%)$ & $1,681(25 \%)$ & \\
\hline $2008-2011$ & $242(27 \%)$ & $1,778(26 \%)$ & \\
\hline $2012-2014$ & $225(26 \%)$ & $1,616(24 \%)$ & \\
\hline Re-operation & $154(17 \%)$ & $1,372(20 \%)$ & 0.038 \\
\hline One-year mortality & $231(26 \%)$ & $1,009(15 \%)$ & $\varangle 0.001$ \\
\hline
\end{tabular}

aRe-evacuation of a chronic subdural hematoma within 1 year of the primary evacuation 
Table 3: Case-mix adjusted association between exposure

(dementia) and one-year case-fatality among cases

\begin{tabular}{|l|l|l|}
\hline Group & OR $\mathbf{( 9 5 \%} \mathbf{~ C l )}$ & p-value \\
\hline All patients & $1.50(1.26-1.78)$ & $\varangle 0.001$ \\
\hline $60-69$ years & $3.21(1.59-6.47)$ & 0.001 \\
\hline $70-79$ years & $1.77(1.26-2.50)$ & 0.001 \\
\hline $80-89$ years & $1.39(1.11-1.75)$ & 0.004 \\
\hline $90+$ years & $1.20(0.73-1.96)$ & 0.47 \\
\hline $\begin{array}{l}\text { Note. Logistic regression analyses adjusted for age, sex, year of } \\
\text { primary operation, re-operation and hospital level of care. } \\
\text { Abbreviations: OR: Odds Ratio; Cl: Confidence Interval }\end{array}$ \\
\hline
\end{tabular}




\section{FIGURE LEGENDS}

Figure 1: Flow chart. Abbreviations: ICD=International Statistical Classification of Diseases and Related Health Problems, NCSP-F=NOMESCO Classification of Surgical Procedures Finland, $A A D 10=$ Evacuation of chronic subdural hematoma, $C S D H=C h r o n i c$ Subdural Hematoma.

Figure 2: Left: Hospitalization-based occurrence rates (per 100,000 persons) of chronic subdural hematoma evacuation in Finland. The population at risk includes the whole Finnish population in the specific age-band. Right: Proportion of patients undergoing CSDH surgery with a pre-existing diagnosis of dementia. The proportion increased from $9.7 \%$ in 1997 to $12.2 \%$ in $2012-2014$. 

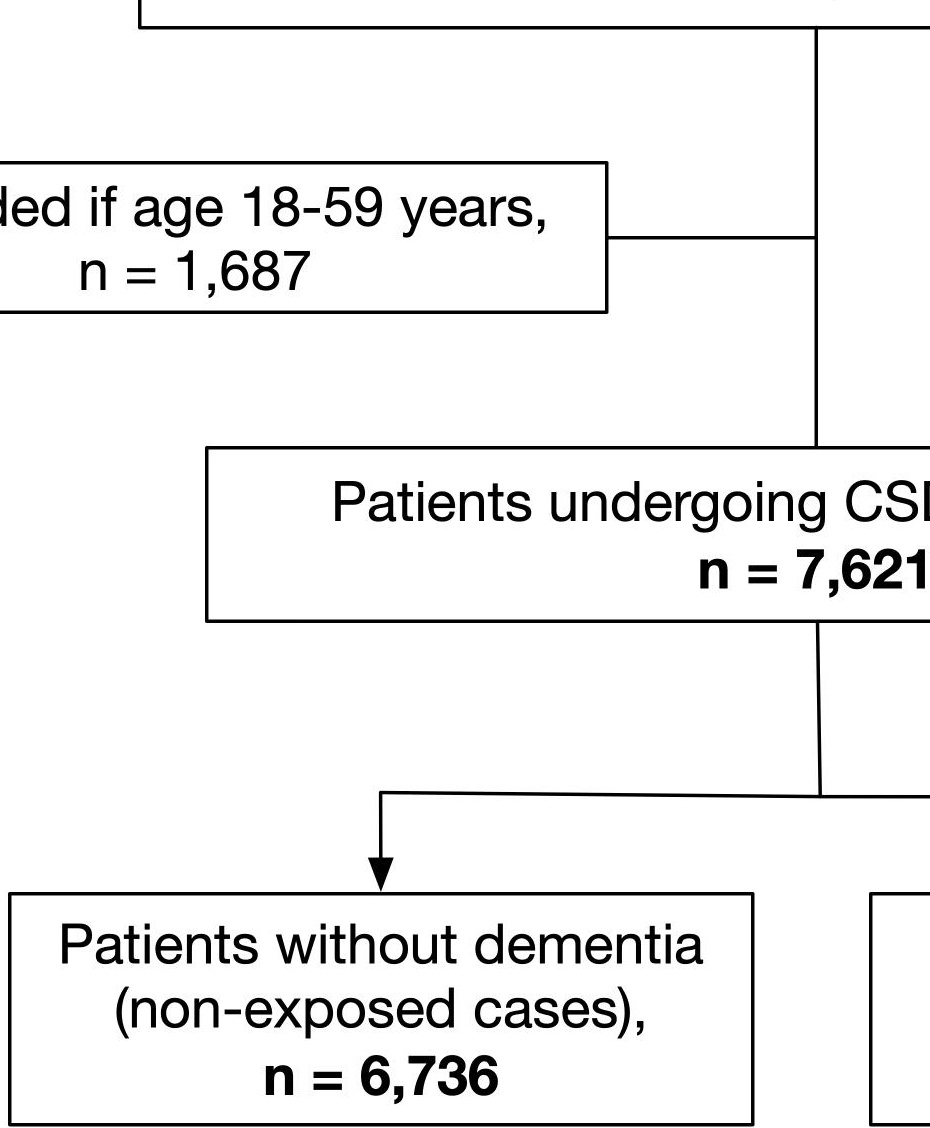

Patients with dementia (exposed cases),

Matched by: i) age, ii) sex, iii)

year of first hospitalisation with

$$
n=6,736
$$$$
\mathbf{n}=\mathbf{8 8 5}
$$

Finnish Care Register for Health Care 1987-2014

ICD-9: 290, 331, 797; ICD-10: G30, F00-03,

$$
n=175,883
$$

Excluded if previously diagnosed head injury (ICD-9: 850-854, ICD-10: S06.X), $n=15,715$ 


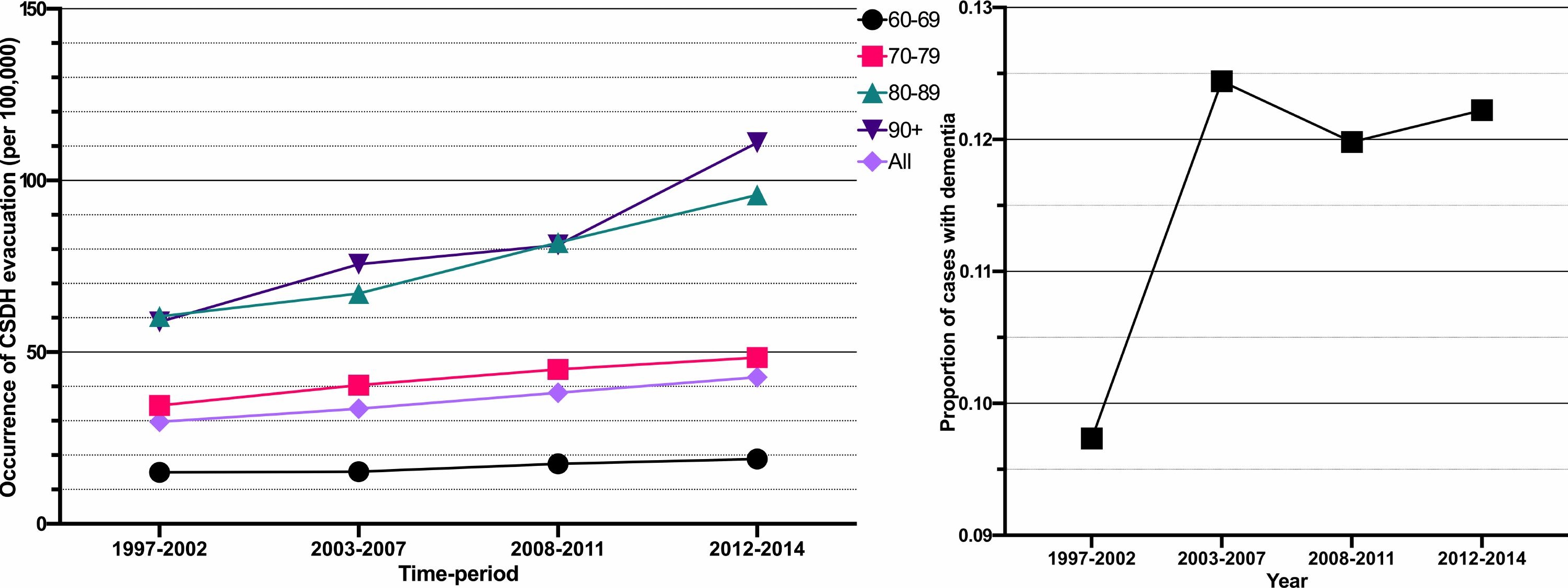


Mortality of older patients with dementia after surgery for chronic subdural hematoma: a nationwide study

Supplementary data 


\section{Page of contents}

Appendix 1: Supplementary text

Appendix 2: Table 4

Appendix 3: Table 5

Appendix 4: Full list of references 


\section{Appendix 1: Supplementary text}

\section{METHODS}

\section{Study design}

In summary, the Finnish Care Register for Health Care database is upheld by the National Institute for Health and Welfare in Finland and contains data on every person treated in all hospitals in Finland from 1969 onwards. Intracranial procedures are exclusively performed in selected tax-funded public hospitals - primarily the five University Central Hospitals and the network of tertiary, regional Central hospitals. Thus, the database comprehensively includes patients hospitalised for CSDH evacuation.

\section{Case definition}

We defined CSDH evacuation as an International Statistical Classification of Diseases and Related Health Problems (ICD) 10 diagnosis of S06.5 or I62.0 (ICD-9 has been in use in Finland during 1987-1995 and ICD-10 has been in use in Finland since 1996) with a combined NOMESCO Classification of Surgical Procedures Finland (NCSP-F) of AAD10 ("evacuation of chronic subdural hematoma", NCSP-F has been in use in Finland since 1997). Thus, a "case" is defined as the combination of an S06.5 or I62.0 ICD-10 diagnosis and an AAD10 NCSP-F code.

\section{Definition of exposure}

From the Care Register for Health Care, we identified all persons that had been hospitalised, for any reason, with a new diagnosis of dementia (ICD-9: 290, 331, 791; ICD10: G30, F00, F01, F02, F03) between 1 January 1987 and 31 December 2014. We defined the admission date for the hospitalisation with the new dementia diagnosis as the date of diagnosis. We defined cases as having a pre-existing diagnosis of dementia if the 
time of dementia diagnosis was before or within 1-year of CSDH evacuation. We chose the 1-year post-surgery time as hospitalisation due to trauma or impaired general condition may be the first signs of dementia leading to the diagnosis. The diagnoses of dementia in the Care Register for Health Care have been shown to be very accurate [21].

\section{Exposed controls}

Through the Care Register for Health Care search (see above), we identified persons hospitalised due to any reason with a primary or a secondary discharge diagnosis of dementia during 1987-2014 (ICD-9: 290, 331, 797; ICD-10: G30, F00, F01, F02, F03), and without a head injury diagnosis (ICD-9: 850-854, ICD-10 S06.X). We used a four to one matching ratio in order to adjust for mortality among the exposed controls between the date of exposure (dementia diagnosis) and time of CSDH evacuation, and to provide adequate statistical power for the analysis. We did not include the case-control sets if all four exposed controls had died before the exposed case underwent CSDH evacuation. Thus, if the exposed case had at least one exposed control alive at the time of CSDH surgery, a matched analysis was enabled.

\section{Statistical analyses}

We present descriptive characteristics as categorical or continuous data. We tested continuous variables for skewness and found them to be skewed. Thus, continuous variables are reported as medians with interquartile ranges (IQR). We compared categorical data between groups using a two-sided $x^{2}$ test, adjusted for the Bonferroni correction when appropriate. We compared continuous data between groups using a nonparametric Mann-Whitney $\mathrm{U}$ or a Kruskal-Wallis $\mathrm{H}$ test. For the time-trend analyses, we 
divided the patients into equally quartiles based upon year of treatment (1997-2002, 20032007, 2008-2011, 2012-2014).

We calculated hospital-based occurrence rates (per 100,000 persons) for CSDH evacuation. The hospital-based occurrence rates were calculated separately in the following age-groups: 60-69, 70-79, 80-89 and 90+, without age-adjustment within agebands. The age-band specific occurrence calculation was based upon the whole Finnish population (http://sotkanet.fi). We further assessed trends in proportion of exposed cases during the study period and assessed trend statistics by the Jonckheere-Terpsta test.

In the primary case-only analysis, we used binary logistic regression, adjusting for variables that significantly differed $(p<0.05)$ between dementia and non-dementia patients and 1-year survivors and non-survivors in univariate analyses. We further tested the association between dementia and mortality separately in the pre-defined age-groups (6069, 79-79, 80-89, 90+), adjusting for the same covariates. We also used Cox proportional Hazards models to estimate hazard ratio $(\mathrm{HR})$, with $95 \%$ confidence intervals $(\mathrm{Cl})$ for 1year mortality. We derived log-log plots of survival curves to verify that the proportional hazards assumption was not violated. In the exposed case-control analysis, we compared 1 -year mortality between cases and controls using a $x^{2}$ test.

We conducted the study according to the Strengthening the Reporting of Observational Studies in Epidemiology (STROBE) Statement [22].

\section{Ethical Statement}


The National Institute for Health and Welfare (THL/1326/5.05.00/2015) approved of the study and waived the need for patient consent, in accordance with Finnish national legislation. Statistics Finland (Dnro TK-53-1179- 16) and the Population Register Centre (Dnro 1873/410/16) granted us access to their databases. The Finnish Office of the Data Protection Ombudsman (Dnro 2794/402/2015) approved the data collection and combining of data registries. 
Appendix 2 - Table 4: Characteristics for cases according to study year quartile

\begin{tabular}{|c|c|c|c|c|c|}
\hline Variable & $\begin{array}{l}1997-2002 \\
(n=1,839)\end{array}$ & $\begin{array}{l}\mathbf{2 0 0 3 - 2 0 0 7} \\
(\mathrm{n}=1,921)\end{array}$ & $\begin{array}{l}\text { 2008-2011 } \\
(\mathrm{n}=2,020)\end{array}$ & $\begin{array}{l}\mathbf{2 0 1 2 - 2 0 1 4} \\
(\mathrm{n}=1,841)\end{array}$ & P-value \\
\hline Age, median (IQR) & $76(70-82)$ & $77(71-82)$ & $77(70-83)$ & $78(70-84)$ & $<0.001$ \\
\hline $60-69$ & $439(24 \%)$ & $416(22 \%)$ & $466(23 \%)$ & $417(23 \%)$ & $<0.001$ \\
\hline $70-79$ & $762(41 \%)$ & $781(41 \%)$ & $732(37 \%)$ & $621(34 \%)$ & \\
\hline $80-89$ & $560(31 \%)$ & $618(32 \%)$ & $713(35 \%)$ & $667(36 \%)$ & \\
\hline $90+$ & $78(4 \%)$ & $106(5 \%)$ & $109(5 \%)$ & $136(7 \%)$ & \\
\hline \multicolumn{6}{|l|}{ Sex } \\
\hline Female & $652(36 \%)$ & 659 (34\%) & $677(34 \%)$ & $623(34 \%)$ & 0.61 \\
\hline Male & $1,187(64 \%)$ & $1,262(66 \%)$ & $1,353(66 \%)$ & $1,218(66 \%)$ & \\
\hline \multicolumn{6}{|l|}{ Hospital level } \\
\hline University hospital & $1,496(81 \%)$ & $1,689(88 \%)$ & $1,871(93 \%)$ & $1,751(95 \%)$ & $<0.001$ \\
\hline Central hospital & $343(19 \%)$ & $232(12 \%)$ & $149(7 \%)$ & $90(5 \%)$ & \\
\hline Re-operation ${ }^{a}$ & $345(19 \%)$ & $405(21 \%)$ & $428(21 \%)$ & $348(19 \%)$ & 0.10 \\
\hline Dementia $^{\text {b }}$ & $179(10 \%)$ & $239(12 \%)$ & $242(12 \%)$ & $225(12 \%)$ & 0.036 \\
\hline 1-year mortality & $323(18 \%)$ & $305(16 \%)$ & $307(15 \%)$ & $305(16 \%)$ & 0.23 \\
\hline
\end{tabular}


Appendix 3 - Table 5: Multivariable logistic regression analysis for risk factors of 1-year case-fatality of

cases

\begin{tabular}{|c|c|c|}
\hline Variable & OR $(95 \% \mathrm{Cl})$ & P-value \\
\hline Age (per year) & $1.08(1.06-1.08)$ & $<0.001$ \\
\hline \multicolumn{3}{|l|}{ Sex } \\
\hline Male & 1.00 (Reference category) & \\
\hline Female & $0.81(0.71-0.92)$ & 0.002 \\
\hline \multicolumn{3}{|l|}{$\begin{array}{l}\text { Year of primary } \\
\text { operation }\end{array}$} \\
\hline 1997-2002 & 1.00 (Reference category) & \\
\hline 2003-2007 & $0.84(0.70-0.99)$ & 0.047 \\
\hline 2008-2011 & $0.78(0.65-0.93)$ & 0.005 \\
\hline 2012-2014 & $0.82(0.69-0.99)$ & 0.036 \\
\hline \multicolumn{3}{|l|}{ Re-operation ${ }^{\mathrm{a}}$} \\
\hline No & 1.00 (Reference category) & \\
\hline Yes & $0.67(0.56-0.79)$ & $<0.001$ \\
\hline \multicolumn{3}{|l|}{$\begin{array}{l}\text { Hospital level of } \\
\text { care }\end{array}$} \\
\hline Central hospital & 1.00 (Reference category) & \\
\hline University hospital & $0.93(0.76-1.13)$ & 0.45 \\
\hline \multicolumn{3}{|l|}{ Dementia $^{b}$} \\
\hline No & 1.00 (Reference category) & \\
\hline Yes & $1.50(1.26-1.78)$ & $<0.001$ \\
\hline \multicolumn{3}{|c|}{$\begin{array}{l}\text { Re-evacuation of a chronic subdural hematoma within 1-year of the primary } \\
\text { evacuation. } \\
\text { bementia diagnosis before or within } 1 \text {-year of the chronic subdural hematoma } \\
\text { evacuation. } \\
\text { Abbreviations: OR: Odds Ratio; Cl: Confidence Interval. }\end{array}$} \\
\hline
\end{tabular}




\section{Appendix 4: Full list of references}

1. Connolly BJ, Pearce LA, Hart RG. Vitamin K Antagonists and Risk of Subdural Hematoma. Stroke 2014; 45: 1672-1678.

2. Gaist D, García Rodríguez LA, Hellfritzsch $M$ et al. Association of Antithrombotic Drug Use With Subdural Hematoma Risk. JAMA 2017; 317: 836.

3. Adelborg K, Grove EL, Sundbøll J, Laursen M, Schmidt M. Sixteen-year nationwide trends in antithrombotic drug use in Denmark and its correlation with landmark studies. Heart 2016; 102: 1883-1889.

4. Kolias AG, Chari A, Santarius T, Hutchinson PJ. Chronic subdural haematoma: modern management and emerging therapies. Nat Rev Neurol 2014; 10: 570-578.

5. Prince M, Bryce R, Albanese E, Wimo A, Ribeiro W, Ferri CP. The global prevalence of dementia: A systematic review and metaanalysis. Alzheimer's Dement 2013; 9: 63-75.e2.

6. Pringsheim T, Fiest K, Jette N. The international incidence and prevalence of neurologic conditions: how common are they? Neurology 2014; 83: 1661-4.

7. Derby CA, Katz MJ, Lipton RB, Hall CB. Trends in Dementia Incidence in a Birth Cohort Analysis of the Einstein Aging Study. JAMA Neurol 2017; 74: 1345-1351.

8. Langa KM. Is the risk of Alzheimer's disease and dementia declining? Alzheimers Res Ther 2015; 7: 34.

9. Prince MJ, Wu F, Guo Y et al. The burden of disease in older people and implications for health policy and practice. Lancet 2015; 385: 549-562.

10. Lindfors M, Vehviläinen J, Siironen J, Kivisaari R, Skrifvars MB, Raj R. Temporal changes in outcome following intensive care unit treatment after traumatic brain injury: a 17-year experience in a large academic neurosurgical centre. Acta Neurochir (Wien) 2018; 160: 2107-2115.

11. Korja M, Raj $R$, Seppä $\mathrm{K}$ et al. Glioblastoma survival is improving despite increasing incidence rates: a nationwide study between 2000 and 2013 in Finland. Neuro Oncol 2019; 21: 370-379.

12. Kotkansalo A, Leinonen V, Korajoki M, Salmenkivi J, Korhonen K, Malmivaara A. Surgery for degenerative cervical spine disease in Finland, 1999-2015. Acta Neurochir (Wien) 2019; 161.

13. Rauhala M, Luoto TM, Huhtala $\mathrm{H}$ et al. The incidence of chronic subdural hematomas from 1990 to 2015 in a defined Finnish population. J Neurosurg 2019; 132: 1147-1157.

14. Adhiyaman V, Chattopadhyay I, Irshad F, Curran D, Abraham S. Increasing incidence of chronic subdural haematoma in the elderly. QJM 2017; 110: 375-378.

15. Kudo H, Kuwamura K, Izawa I, Sawa H, Tamaki N. Chronic Subdural Hematoma in Elderly People: Present Status on Awaji Island and Epidemiological Prospect. Neurol Med Chir (Tokyo), 1992.

16. Reponen E, Korja M, Niemi T, Silvasti-Lundell M, Hernesniemi J, Tuominen H. Preoperative identification of neurosurgery patients with a high risk of in-hospital complications: a prospective cohort of 418 consecutive elective craniotomy patients. J Neurosurg 2015; 123: 594-604. 
17. Miranda LB, Braxton E, Hobbs J, Quigley MR. Chronic subdural hematoma in the elderly: not a benign disease. J Neurosurg 2011; 114: 72-76.

18. Jones S, Kafetz K. A prospective study of chronic subdural haematomas in elderly patients. Age Ageing 1999; 28: 519-21.

19. Ramachandran R, Hegde T. Chronic subdural hematomas-causes of morbidity and mortality. Surg Neurol 2007; 67: 367-372.

20. Raj R, Kaprio J, Korja M, Mikkonen ED, Jousilahti P, Siironen J. Risk of hospitalization with neurodegenerative disease after moderate-to-severe traumatic brain injury in the working-age population: A retrospective cohort study using the Finnish national health registries. PLoS Med 2017; 14.

21. Solomon A, Ngandu T, Soininen $H$, Hallikainen MM, Kivipelto M, Laatikainen $T$. Validity of dementia and Alzheimer's disease diagnoses in Finnish national registers. Alzheimer's Dement 2014; 10: 303-309.

22. Vandenbroucke JP, von EIm E, Altman DG et al. Strengthening the Reporting of Observational Studies in Epidemiology (STROBE): Explanation and Elaboration. PLoS Med 2007; 4: e297.

23. Abe $\mathrm{Y}$, Maruyama $\mathrm{K}$, Yokoya $\mathrm{S}$ et al. Outcomes of chronic subdural hematoma with preexisting comorbidities causing disturbed consciousness. J Neurosurg 2017; 126 : 1042-1046.

24. Christopher E, Poon MTC, Glancz LJ et al. Outcomes following surgery in subgroups of comatose and very elderly patients with chronic subdural hematoma. Neurosurg Rev 2019; 42: 427-431.

25. Kwon C-S, Al-Awar O, Richards O, Izu A, Lengvenis G. Predicting Prognosis of Patients with Chronic Subdural Hematoma: A New Scoring System. World Neurosurg 2018; 109: e707-e714.

26. Shimizu K, Sadatomo T, Hara T, Onishi S, Yuki K, Kurisu K. Importance of frailty evaluation in the prediction of the prognosis of patients with chronic subdural hematoma. Geriatr Gerontol Int 2018; 18: 1173-1176.

27. Bartek J, Sjåvik K, Ståhl $\mathrm{F}$ et al. Surgery for chronic subdural hematoma in nonagenarians: A Scandinavian population-based multicenter study. Acta Neurol Scand 2017; 136: 516-520.

28. De Bonis $\mathrm{P}$, Olei $\mathrm{S}$, Mongardi $\mathrm{L}$ et al. Chronic subdural hematoma in patients aged 80 years and older: A two-centre study. Clin Neurol Neurosurg 2018; 170: 88-92.

29. Dobran M, Marini A, Nasi D et al. Clinical Outcome of Patients Over 90 Years of Age Treated for Chronic Subdural Hematoma. J Korean Neurosurg Soc 2019;

30. Panula J, Pihlajamäki H, Mattila VM et al. Mortality and cause of death in hip fracture patients aged 65 or older: a population-based study. BMC Musculoskelet Disord 2011; 12: 105.

31. Diehr P, Williamson J, Patrick DL, Bild DE, Burke GL. Patterns of Self-Rated Health in Older Adults Before and After Sentinel Health Events. 2001.

32. Dumont TM, Rughani AI, Goeckes T, Tranmer BI. Chronic Subdural Hematoma: A Sentinel Health Event. World Neurosurg 2013; 80: 889-892.

33. Baldereschi M, Di Carlo A, Maggi S et al. Dementia is a major predictor of death 
among the Italian elderly. ILSA Working Group. Italian Longitudinal Study on Aging. Neurology 1999; 52: 709-13.

34. Katzman R, Hill LR, Yu ES et al. The malignancy of dementia. Predictors of mortality in clinically diagnosed dementia in a population survey of Shanghai, China. Arch Neurol 1994; 51: 1220-5.

35. Qiu C, Bäckman L, Winblad B, Agüero-Torres H, Fratiglioni L. The influence of education on clinically diagnosed dementia incidence and mortality data from the Kungsholmen Project. Arch Neurol 2001; 58: 2034-9.

36. Santarius T, Kirkpatrick PJ, Ganesan D et al. Use of drains versus no drains after burr-hole evacuation of chronic subdural haematoma: a randomised controlled trial. Lancet 2009; 374: 1067-1073.

37. Keskimäki I, Aro S. Accuracy of data on diagnoses, procedures and accidents in the Finnish Hospital Discharge Register. Int Jx Heal Sci 1991; 2: 15-21.

38. Sund R. Quality of the Finnish Hospital Discharge Register: A systematic review. Scand J Public Health 2012; 40: 505-515.

39. Tommiska P, Lönnrot K, Raj R, Luostarinen T, Kivisaari R. Transition of a Clinical Practice to Use of Subdural Drains after Burr Hole Evacuation of Chronic Subdural Hematoma: The Helsinki Experience. World Neurosurg 2019; 129: e614-e626.

40. Wu Y-T, Fratiglioni L, Matthews FE et al. Dementia in western Europe: epidemiological evidence and implications for policy making. Lancet Neurol 2016; 15: 116-124.

41. Erkinjuntti T, Remes A, Rinne J, Soininen H, eds. Muistisairaudet. 2nd ed. Kustannus oy Duodecim, 2015.

42. Kim SO, Jung S II, Won YS, Choi CS, Yang JY. A Comparative Study of Local versus General Anesthesia for Chronic Subdural Hematoma in Elderly Patients Over 60 Years. Korean J Neurotrauma 2013; 9: 47.

43. Surve RM, Bansal S, Reddy M, Philip M. Use of Dexmedetomidine Along With Local Infiltration Versus General Anesthesia for Burr Hole and Evacuation of Chronic Subdural Hematoma (CSDH). J Neurosurg Anesthesiol 2017; 29: 274-280. 